\title{
Persistent Hypoglycemia and Seizures in Two Months Old Infant Due to Recurrent Hyper insulinemic Hypoglycemia
}

\author{
Dr. Edwin Dias \\ Professor \& HOD \\ Srinivas Institute of Medical Science and Research Centre, Mangalore, India, \& Adjunct \\ Professor, Srinivas University, Mangalore, India. \\ Email: edwindias@gmail.com
}

Area/Section: Health Science.

Type of the Paper: Case Report.

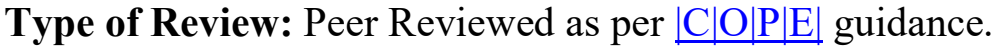

Indexed in: OpenAIRE.

DOI: http://doi.org/zenodo.

Google Scholar Citation: IJHSP

\section{How to Cite this Paper:}

Edwin Dias. (2020). Persistent Hypoglycemia and Seizures in Two Months Old Infant Due to Recurrent Hyper insulinemic Hypoglycemia. International Journal of Health Sciences and Pharmacy (IJHSP), 4(2), 29-33. DOI: http://doi.org/zenodo.

International Journal of Health Sciences and Pharmacy (IJHSP)

A Refereed International Journal of Srinivas University, India.

(C) With Author.

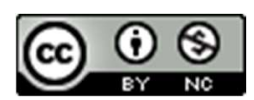

This work is licensed under a Creative Commons Attribution-Non Commercial 4.0 International License subject to proper citation to the publication source of the work.

Disclaimer: The scholarly papers as reviewed and published by the Srinivas Publications (S.P.), India are the views and opinions of their respective authors and are not the views or opinions of the SP. The SP disclaims of any harm or loss caused due to the published content to any party. 


\title{
Persistent Hypoglycemia and Seizures in Two Months Old Infant Due to Recurrent Hyperinsulinemic Hypoglycemia
}

\author{
Dr. Edwin Dias \\ Professor \& HOD \\ Srinivas Institute of Medical Science and Research Centre, Mangalore, India, \& Adjunct \\ Professor, Srinivas University, Mangalore, India. \\ Email: edwindias@gmail.com
}

\begin{abstract}
Persistent hyperinsulinemic hypoglycaemia is the most common cause of recurrent hypoglycaemia. Neonatal hypoglycemia, is a heterogeneous disorder with plasma glucose level of less than $30 \mathrm{mg} / \mathrm{dL}$ in first $24 \mathrm{hrs}$ of life and less than $40 \mathrm{mg} / \mathrm{dL}$ thereafter, is the most common metabolic cause in newborns. The most important feature of neurologic dysfunction in neonatal period is the occurrence of seizures which can be due to metabolic disorders, genetic disorders, intracranial infections, malformation syndromes, benign neonatal seizures, hemorrhage. Here, we provide a description of a 2 months old infant with Persistent Hypoglycemia and Seizures, treated with hypoglycemic management and antiepileptic drugs.
\end{abstract}

Keywords: Persistent hyperinsulinemic Hypoglycemia, seizures, Infants.

\section{INTRODUCTION :}

Hypoglycemia is the most common metabolic cause in neonates with blood glucose value less than $30 \mathrm{mg} / \mathrm{dL}$ in the first day and $40 \mathrm{mg} / \mathrm{dl}$ is accepted as the value internationally [1]. Children with hypoglycemia might be asymptomatic or present with severe CNS and cardiopulmonary disturbances; the most common clinical manifestations includes altered level of consciousness, seizure, vomiting, unresponsiveness and lethargy [13] Causes of hypoglycemia in neonates differ from those in older infants and children, which includes; changes in hormone secretion, inadequate lipid stores as a source of amino acids for release of fatty acids, insufficient muscle stores as a source of amino acids for gluconeogenesis, persistent hyperinsulinemic hypoglycemia of infancy (PHHImost common cause of hypoglycemia in the first 3 months of life). Hypoglycemia can occur in infants who previously have suffered asphyxia, who are offspring of diabetic mothers or who are low birth weight for gestational age [2]. Infants in first or second life may be asymptomatic or may have CNS and cardiopulmonary problems, the signs and symptoms seen in these neonates includes; hypotonia, lethargy, poor feeding, seizures, cyanosis, apnea, congestive heart failure [8]. Early cases were diagnosed with laboratory studies which includes; serum or plasma glucose levels, serum insulin, urine for organic acid analysis and screening for metabolic errors by electrospray ionization- tandem mass spectrometry in asymptomatic cases allows earlier identification of clearly defined inborn errors of metabolism. SGA infants are at risk of the adverse effects of hypoglycaemia by virtue of impaired gluconeogenesis and ketogenesis, both immediately after birth and in response to persistent hypoglycemia [4]. In order to prevent complications of neurologic damage hypoglycemia as to be treated as soon as possible. Repeated and prolonged very low plasma glucose concentrations particularly associated with conditions of excessive insulin secretion [15].

Most neonatal seizures arise over only for a few days and fewer than half of affected infants develops seizures later and such neonatal seizures can be considered acute symptomatic. Neonatal seizure classification includes clonic seizures, tonic seizures, and myoclonic seizures [5]. Prognosis is determined by the etiology of the neonatal seizures based on EEG. Complications of neonatal seizures includes; cerebral palsy/spasticity, cerebral atrophy, feeding difficulties, epilepsy [9]. Seizure medication concentration should be monitored during the acute period and the drugs (AEDs) are often discontinued between the ages 3 and 6 months depending on EEG [10]. We present a case of 
persistent hypoglycemia and seizures in 2 months old infant.

\section{CASE REPORT :}

A 2 months old male infant presented with history of generalize seizures at 2 months of life which was sudden in onset. He had been diagnosed as hyperinsulinemic hypoglycemia. He has been referred here for EEG study and PET scan.

Past history shows; 2 months old male infant, 2nd child of NCM with term gestation, no history of GDM/Hypothyroidism in mother, SVD with term gestation with cry at birth. On day of 2 nd life he had an episode of seizure with low RBS $(38 \mathrm{mg} / \mathrm{dL})$. He was treated with dextrose and was discharged after 6 days. He was normal for two months. On 19/07/2020 he developed seizure episodes with associated low sugars $(<50 \mathrm{mg} / \mathrm{dL})$, he was admitted. Neuro USG and abdominal USG scan were normal. MRI revealed signs of hypermyelination with altered signal intensities. Insulin was found to 20 with corresponding RBS of $30 \mathrm{mg} / \mathrm{DL}$. Serum ammonia, calcium were normal. He was initially treated with dextrose and hydrocortisone was started. Once these were stopped, he developed seizures again. Hence, he was started on oral diazoxide at $5 \mathrm{mg} / \mathrm{kg} /$ day and showed good response with no further episodes of hypoglycemia.

Feeding and immunization history was not significant. Vitals were stable. Weight $5 \mathrm{~kg}$, head circumference $37 \mathrm{cms}$, length $56 \mathrm{cms}$. No dysmorphic facies or neurocutaneous markers. Eyes were normal. Other general examination did not reveal any significance. Visual acuity and hearing were normal. CNS examination, cranial nerves were normal, motor system showed normal power as per the age. Cranial and spine axis was normal.

Investigations: $\mathrm{CBC}$, Serum electrolytes, RBS, blood sugar -glucometry, serum calcium, potassium, magnesium, TC, TSH, Free T4, triglycerides, C-reactive protein, procalcitonin, LFT, renal function test, serum cortisol, USG abdomen, CSF sugar and protein and gramstain, Neurosonogram, lactate plasma, plasma ammonia, urine culture and sensitivity (no growth), MRI brain were normal. Peripheral smear shows normocytic normochromic anemia and mild neutrophilic leukocytosis with shift to left. DNA testing for RILD levels negative (ABCC8 and KCNJ11). EEG record showed left parietal epileptiform abnormalities in sleep along with mild degree of focal nonspecific disturbance of electrical function (left $>$ right). Infant as treated with hypoglycemia management, GRBS monitoring and glucagon injection.

\section{DISCUSSION :}

In summary, we have a 2-month-old male infant who was immunized, with a past medical history prior to the onset of her current ailment. Approximately on day of 2 nd life he had an episode of seizure with low RBS. He was treated with dextrose and was discharged after 6 days. He was normal for two months. On 19/07/2020 he developed seizure episodes with associated low sugars $(<50 \mathrm{mg} / \mathrm{dL})$, he was admitted. Neuro USG and abdominal USG scan were normal. MRI revealed signs of hypermyelination with altered signal intensities. Insulin was found to 20 with corresponding RBS of $30 \mathrm{mg} / \mathrm{DL}$. He was initially treated with dextrose and hydrocortisone was started. Once all these were stopped, he developed seizures again. Hence, he was started on oral diazoxide at $5 \mathrm{mg} / \mathrm{kg} /$ day and showed good response with no further episodes of hypoglycemia. Later in his, developed the same complaints of generalized seizure and was diagnosed hyperinsulinemia hypoglycemia. The infant was referred for management of recurrent Hyperinsulinemic hypoglycemia. At hospital DNA isolation testing was done for both child and parents. CBC, Serum electrolytes, RBS, blood sugar -glucometry, serum calcium, potassium, magnesium, TC, TSH, Free T4, triglycerides, Creactive protein, procalcitonin, LFT, renal function test, serum cortisol, USG abdomen, CSF sugar and protein and gramstain, Neurosonogram, lactate plasma, plasma ammonia, urine culture and sensitivity (no growth), MRI brain were normal. Peripheral smear shows normocytic normochromic anemia and mild neutrophilic leukocytosis with shift to left. Peripheral smear shows normocytic normochromic anemia and mild neutrophilic leukocytosis with shift to left. DNA testing for RILD levels negative (ABCC8 and KCNJ11). EEG record showed left parietal epileptiform abnormalities in sleep along with mild degree of focal non-specific disturbance of electrical function (left $>$ right). Baseline and stimulated cortisol levels, corrected calcium and routine investigations were also sent. Pediatric neurology opinion was taken and routine EEG advised. His EEG record showed left parietal epileptiform abnormalities in sleep along with mild degree of focal non-specific disturbance of electrical function (left >right). GRBS monitoring was done 
and in view of his condition it was advised to continue Phenobarbitone and MRI has to be repeated if seizures occurred in the presence of normoglycemia. Hypoglycemia is often a persistent problem in the newborn. Significant hypoglycemia can lead to optic and mental disorders, epilepsy, and brain damage. Hypoglycemia causes convulsions by increasing glutamate, the main excitatory neurotransmitter of the brain. The genetic abnormalities in hyperinsulinemic hypoglycaemia is $\mathrm{ABCC} 8$, KCNJ11, GCK, SCHAD, GLUD1, SLC16A1, HNF1A, HNF4A and UCP2 leads to congenital form of hyperinsulinemic hypoglycaemia. Hyperinsulinemia is also the cause of hypoglycaemia in transistional nenonatal hypoglycaemia and in persistent hypoglycaemia in various groups of high risk nenonates. In hypoglycemia, the main excitatory amino acid glutamate is deficiently reabsorbed due to its extreme secretion in the synaptic area and insufficiency of energy-dependent channels and thus leads to increased amounts of secondary extracellular glutamate which in turn induces convulsions. Phenobarbital was effectively proved to be most useful anticonvulsant agent in the treatment of generalized convulsions in the newborn babies. Early diagnosis and management of hyperinsulinemic hypoglycaemia is the cornerstone for prevention of hypoglycaemia induced neuronal injury. Management of $\mathrm{HH}$ remains a challenge due to lack of facilities for genetic studies and 18F- DOPA-PET scan [2].

\section{CONCLUSION :}

Persistent hypoglycemia and seizures in a 2month-old infant is a diagnostic and management challenge and often requiring continuous antiepileptic treatment [18]. Analysis of blood sample collected at the time of hypoglycaemic episode for intermediary metabolites and hormones is critical for diagnosis and treatment [13].

\section{REFERENCES :}

[1] Sann L. Neonatal hypoglycemia. Biol Neonate. 1990;58 (Supp 1);16-21. Straussman S, Levitsky LL. Neonatal hypoglycemia. Curr Opin Endocrinology Diabetes Obes. 2010; 17; 20-4.

[2] Hussain K. Diagnosis and Management of hyperinsulinemic hypoglycemia of infancy. Horn Res 2008;69:2-13.

[3] Vannucci R.C., Vannucci S. J. Hypoglycemic brain injury. Semin Neonatal 2001;6:147-55.

[4] Sacks D.B., Arnold M, Bakris G.L., Etal. Guidelines and recommendations for laboratory analysis in the diagnosis and management of diabetic mellitus. Diabetes care 2011;34:e61-99.

[5] Hawdon J.M., Ward Platt M.P., Aynsley Green A. Prevention and management of neonatal hypoglycemia. Arch Dis Child. 1994;70:F60-4.

[6] Hauser W.A. (2001). Epidemiology of epilepsy in children. In: Pellock JM, Dodson WE, Bourgeois BFD. Eds. Pediatric Epilepsy: Diagnosis and therapy, 2nd ed. New York: Demos Medical Publishing, inc; 81-96.

[7] Ghosh A, Banerjee I, Morris AA. (2016). Recognition, assessment and management of hypoglycemia in childhood. Arch did child, 101:575-80. 10.1136/archischild-2015-308337.

[8] Palladio A.A., Bennet M.J., Stanley C.A. (2008). Hyperinsulinism in infancy and childhood: when an insulin level is not always enough. Clin Chem, 54:256-63. 10.1373/clinched.2007.098988.

[9] Ferrara C.T., Boodhansingh KE, Paradise E, et al. Novel hypoglycemia phenotype in congenital hyperinsulinism due to dominant mutations of uncoupling protein 2. J Clin Endocrinal Metab 2017;102:942-9.

[10] Glaser B, Kesavan P, Hetman M, et al. Familial hyperinsulinism caused by an activating glucokinase mutation. $N$ Engl $j$ Med 1998;338:226-

30.10.1056/NEJM199801223380404.

[11] Huijmans JG, Duran M, Dr Klerk jB, et al, Functional hyperactivity of hepatic glutamate dehydrogenase as a cause of the hyperinsulinism/hyperammonemia syndrome: effect of treatment. Pediatrics 2000;106:596600.10.1542/peds.106.3.596.

[12] Senniappan S, Alexandrescu S, Tatevian N, et al. Sirolimus therapy in infants with severe hyperinsulinemic hypoglycemia. N Engl J Med 2014; 370:1131-1137; 3 DOI: 10.1056/NEJMoa1310967.

[13] Mohammed Z, Hussain K. the genetics basis of congenital hyperinsulinism. J Med Genet. 2009;46;289-99.

[14] Demirbilek H, Rahman SDA, Buyukyilmaz GG, et al. Diagnosis and treatment of hyperinsulinemic hypoglycemia and its implications for paediatric endocrinology. Int $\mathrm{J}$ 
Pediatr Endocrinal 2017;2017;9. 10.1186/s13633017-0048-8.

[15] William W. Hay, Jr, Raju TN, Higins R.D., et al. Knowledge gaps and research needs for understanding and treating neonatal hypoglycemia; workshop report from Eunice Kennedy Shriver national institute of child and human development. J Pediatr 2009;155;612-7.

[16] Stanley, C. A. (2016). Perspective on the genetics and diagnosis of congenital hyperinsulinism disorders. The Journal of Clinical Endocrinology \& Metabolism, 101(3), 815-826.

[17] Nessa, A., Rahman, S. A., \& Hussain, K. (2016). Hyperinsulinemic hypoglycemia-the molecular mechanisms. Frontiers in endocrinology, 7, 29-36.

[18] Sweet, C. B., Grayson, S., \& Polak, M. (2013). Management strategies for neonatal hypoglycemia. The Journal of Pediatric Pharmacology and Therapeutics, 18(3), 199-208. 